\title{
Gamma Radiation Sterilization Reduces the High-cycle Fatigue Life of Allograft Bone
}

\author{
Anowarul Islam MS, Katherine Chapin BS, Emily Moore BS, \\ Joel Ford MD, Clare Rimnac PhD, Ozan Akkus PhD
}

Received: 2 July 2015/Accepted: 2 October 2015/Published online: 13 October 2015

(C) The Association of Bone and Joint Surgeons (B) 2015

\begin{abstract}
Background Sterilization by gamma radiation impairs the mechanical properties of bone allografts. Previous work related to radiation-induced embrittlement of bone tissue has been limited mostly to monotonic testing which does not necessarily predict the high-cycle fatigue life of allografts in vivo.
\end{abstract}

\footnotetext{
The institution of one or more of the authors (AI, CMR, and OA) has received, during the study period, funding from the Musculoskeletal Transplant Foundation.

All ICMJE Conflict of Interest Forms for authors and Clinical Orthopaedics and Related Research ${ }^{(\mathbb{R}}$ editors and board members are on file with the publication and can be viewed on request. Each author certifies that his or her institution approved or waived approval for the human protocol for this investigation and that all investigations were conducted in conformity with ethical principles of research.

This study was performed at Case Orthopaedics Bioengineering Laboratory, Department of Mechanical and Aerospace Engineering, Case Western Reserve University, Cleveland, OH, USA
}

A. Islam, C. Rimnac, O. Akkus ( $\square)$

Department of Mechanical and Aerospace Engineering, Case

Western Reserve University, 10900 Euclid Ave, Cleveland,

OH 44106, USA

e-mail: oxa@case.edu; ozan.akkus@case.edu

K. Chapin, E. Moore, C. Rimnac, O. Akkus

Department of Biomedical Engineering, Case Western Reserve University, Cleveland, OH, USA

\section{E. Moore}

Department of Biomedical Engineering, Columbia University, New York, NY, USA

J. Ford, C. Rimnac, O. Akkus

Department of Orthopaedics, Case Western Reserve University School of Medicine, Cleveland, OH, USA
Questions/Purposes We designed a custom rotatingbending fatigue device to answer the following questions: (1) Does gamma radiation sterilization affect the high-cycle fatigue behavior of cortical bone; and (2) how does the fatigue life change with cyclic stress level?

Methods The high-cycle fatigue behavior of human cortical bone specimens was examined at stress levels related to physiologic levels using a custom-designed rotatingbending fatigue device. Test specimens were distributed among two treatment groups ( $n=6 /$ group); control and irradiated. Samples were tested until failure at stress levels of 25,35 , and $45 \mathrm{MPa}$.

Results At $25 \mathrm{MPa}, 83 \%$ of control samples survived 30 million cycles (run-out) whereas $83 \%$ of irradiated samples survived only 0.5 million cycles. At $35 \mathrm{MPa}$, irradiated samples showed an approximately 19-fold reduction in fatigue life compared with control samples $\left(12.2 \times 10^{6} \pm\right.$ $12.3 \times 10^{6}$ versus $6.38 \times 10^{5} \pm 6.81 \times 10^{5} ; \mathrm{p}=0.046$ ), and in the case of $45 \mathrm{MPa}$, this reduction was approximately 17.5 -fold $\left(7.31 \times 10^{5} \pm 6.39 \times 10^{5}\right.$ versus $4.17 \times$ $\left.10^{4} \pm 1.91 \times 10^{4} ; \mathrm{p}=0.025\right)$. Equations to estimate highcycle fatigue life of irradiated and control cortical bone allograft at a certain stress level were derived.

Conclusions Gamma radiation sterilization severely impairs the high cycle fatigue life of structural allograft bone tissues, more so than the decline that has been reported for monotonic mechanical properties. Therefore, clinicians need to be conservative in the expectation of the fatigue life of structural allograft bone tissues. Methods to preserve the fatigue strength of nonirradiated allograft bone tissue are needed.

Clinical relevance As opposed to what monotonic tests might suggest, the cyclic fatigue life of radiation-sterilized structural allografts is likely severely compromised relative to the nonirradiated condition and therefore should be 
taken into consideration. Methods to reduce the effect of irradiation or to recover structural allograft bone tissue fatigue strength are important to pursue.

\section{Introduction}

Advancements in healthcare during the last decade have increased the number of patients who will survive after trauma and treatment for bone-related diseases, and this will result in the increased use of human bone allografts [55]. Nearly 1 million allografts were used in the United States alone in 2013 [70]. Terminal sterilization is essential for bone allografts to minimize disease transmission and infection. Methods of sterilization such as heat [31, 41, 42, 45, 63], hydrogen peroxide $[15,24]$ and ethylene oxide $[47,57,65]$ can negatively affect allograft mechanical and biological properties. Heat treatment greater than $60{ }^{\circ} \mathrm{C}$ reduces the strength [41, 42, 45, 71, 72] and impairs osteoinductivity [44]. Chemical treatments such as ethylene oxide and hydrogen peroxide also are harmful to osteoinductivity [8, 15, 24, 25, 54, 56]. Gamma radiation sterilization is the current standard given its convenience and efficacy in achieving sterility and the response toward HIV and hepatitis C [12, 14]. Unfortunately, the sterilization process by gamma radiation also impairs the mechanical properties of allografts owing to the scission of collagen molecules in the bone tissue [3, 10, 19, 34, 60].

Gamma radiation-induced embrittlement of bone tissue has been studied; however these investigations have been limited mostly to monotonic loading conditions, involving a single loading episode to fracture either under tension, compression, or bending [22, 35, 46]. Conventional monotonic tests can effectively screen for the effects of treatment conditions (such as radiation mode or dose, radiating dry versus wet bone tissue, radioprotectant effects) and can provide valuable information regarding the extent of the embrittlement of the sterilized allograft $[50,55]$. However, these tests fall short of simulating the dynamic nature of the physiologic loading conditions that are experienced by allografts. As such, they provide limited insight into the functional lifetime of allografts in vivo, where the graft is subjected to repeated loads well below the monotonic failure strength of the bone tissue. Recently Tufekci et al. [69] reported the effect of gamma sterilization on high strain rate compressive behavior of irradiated equine cortical bone. However, this also is a static study, in a high strain rate. Information regarding the fatigue life under cyclic loading cannot be obtained from monotonic tests owing to differences in the evolution of damage between the two loading regimes. Interestingly, there is little information regarding the performance of gamma radiationsterilized allografts under cyclic loading although it is a more physiologically relevant loading mode $[2,3]$.
The fatigue performance of gamma radiation-sterilized bone tissue needs to be assessed to gain insight into the high-cycle fatigue life of cortical bone grafts subjected to ionizing radiation. At $36 \mathrm{kGy}$, Akkus and Belaney [2] reported a 100-fold reduction in fatigue life of human cortical bone in low-cycle regimes. Mitchell et al. [51], in a fatigue crack propagation study, reported that gamma radiation sterilized human cortical bone tissue was less resistant to fatigue crack growth than in the nonirradiated (control) condition. However, the total fatigue lifetime approach (cyclic stress versus total cycles to failure, or S-N approach) evaluates the cycles to initiate the crack (in the absence of a distinct stress concentration) and to grow the crack to failure. Thus, the S-N approach provides complementary insight into the fatigue resistance of a material beyond that which is provided by approaches that assess only fatigue crack propagation. Most current fatigue tests only apply load in uniaxial tension or, more often, compression or three-point bending [59], which are not physiologically relevant loading conditions and overestimate the cycles to failure of cortical bone allograft. The specimens in these studies also lack proper physiologic hydration. Taken together, these studies indicate that fatigue life is substantially vulnerable to impairment by radiation; thus, it is important to characterize the highcycle fatigue performance of gamma radiation-sterilized bone at the clinically relevant radiation dose of $25 \mathrm{kGy}$. In this study, we evaluated high-cycle fatigue behavior of irradiated human cortical bone allograft in a multiaxial loading profile indicative of normal physical activity in a physiologically relevant environment to ask: (1) Does gamma radiation sterilization affect the high-cycle fatigue behavior of cortical bone, and (2) how does the fatigue life change with cyclic stress level?

\section{Materials and Methods}

\section{Human Tissue Collection and Storage}

Twelve human femurs (from males, age range, 36-65 years) from six donors were obtained from the Musculoskeletal Transplant Foundation (Edison, NJ, USA). The femurs were wrapped in $1 \mathrm{X}$ phosphate buffered solution(PBS) soaked gauze pads and stored at $-20{ }^{\circ} \mathrm{C}[11,30]$ until use. Tissue was allowed to equilibrate to room temperature before specimen preparation.

\section{Sample Preparation}

Diaphyses were cut from each femur and then cut perpendicularly along their length into a proximal section and 
a distal section. The two sections then were cut parallel to the length of the diaphysis to produce six to eight pegs. The pegs were used to make hourglass-shaped samples in general accordance with American Society of Testing Materials standard ASTM E466-07 [9] (Fig. 1A). The pegs were inserted in a rotating Tensilkut ${ }^{\circledR}$ lathe (Tensilkut ${ }^{\circledR}$ Engineering, Maryville, TN, USA) and machined with a Sherline CNC milling machine (Sherline Products Inc, Vista, CA, USA). The CNC code and machining practices were optimized to the extent that the diameter of the midregion was cut within an error range of $\pm 50 \mu$. After machining, specimens were polished with 800- and 1200grit paper for 15 and 30 seconds, respectively. The specimens were kept moist throughout all stages of preparation by regularly brushing with PBS to maintain tissue hydration. Finished specimens were wrapped in gauze soaked in PBS and frozen at $-20{ }^{\circ} \mathrm{C}[11,30]$ until tested. Approximately 10 specimens were machined from each donor femur. Specimens were allocated to treatment groups such that the donor pool was homogenously distributed in each group.

\section{Measurement of the Sample Dimensions}

The geometric parameters needed to calculate stress (Equation 1) at the reduced diameter region were measured by using an optical comparator at an accuracy level of 25 $\mu \mathrm{m}$. Specifically, the distance (L) between the middle of the reduced section to the end of the bearing side (Fig. 1A), and diameter (d) of the reduced section (Fig. 1A) were measured.

\section{Experimental Groups}

There were two experimental groups: (1) control and (2) irradiated ( $\mathrm{n}=6$ samples/group). Specimens in each group were tested at three fully reversed cyclic stress levels of 25 , 35 , and $45 \mathrm{MPa}$. For the control group only, specimens also were tested at $55 \mathrm{MPa}(\mathrm{n}=5)$ because control specimens did not fail at $25 \mathrm{MPa}$. Overall, a total of 41 samples were included in the study.

\section{Gamma Sterilization}

All specimens were wrapped individually in gauze pads dipped in calcium-supplemented saline solution and placed in small polyethylene bags. Specimens for the irradiated group were placed in polystyrene coolers filled with dry ice and shipped overnight to a sterilization facility (FTSI [Food Technology Service Inc], Mulberry, FL, USA). The control group specimens also were placed in polystyrene coolers filled with dry ice and kept at $4{ }^{\circ} \mathrm{C}$ until the irradiated specimens were received. The irradiated specimens were received within 2 days of initial shipment. When the shipped samples were returned, the presence of dry ice was confirmed. Dosimetry indicated that the specimens received a minimum radiation dosage of $25 \mathrm{kGy}$ and maximum radiation dosage of $27 \mathrm{kGy}$. The standard dose range for sterilization of bone grafts is $25 \mathrm{kGy}$ to $35 \mathrm{kGy}$ [55], thus, the level of radiation was in the standard range.

\section{Fatigue Testing Apparatus}

A custom accelerated rotating-beam fatigue-loading device was fabricated to conduct fatigue tests of cortical bone specimens under physiologically relevant conditions $[5,17$, 21, 26, 43, 52] (Fig. 1B). The top portion of the specimen was held in a fixed rotating grip and the lower portion of the sample was glued inside a ball bearing, allowing for free rotation of the specimen inside the ball bearing. Stress was applied via a dead weight attached to the bearing by a steel wire. For each cycle, or $360^{\circ}$ rotation, the specimen experienced tension, compression, and shear stresses cyclically owing to the cantilever arrangement (Fig. 1C). The stress levels were varied by adjusting the weight of the hanging mass. The specimens were lowered with a sliding rack into calcium supplemented $1 \mathrm{X}$ PBS solution contained by a corrosion-resistant tank. An immersion heater and thermocouple were incorporated so the user was able to adjust the temperature of the solution. The temperature of the immersion solution was always maintained at $37{ }^{\circ} \mathrm{C}$.

Specimens were thawed at room temperature for approximately 30 minutes in $1 \mathrm{X}$ PBS. Specimens then were acclimated in the solution tank of the fatigue testing device that was filled with calcium supplemented 1X PBS maintained at $37{ }^{\circ} \mathrm{C}$ for another 1 hour before testing. The solution in the tank was changed every day in addition to being pumped through an ultraviolet sterilizer every day for an hour. The $\mathrm{pH}$ was between 7.2 and 7.4.

The stress created at the reduced diameter region was calculated as:

$\sigma=\frac{32 m g\left(\mathrm{~L}-\frac{t}{2}\right)}{\pi d^{3}}$

Where, $\mathrm{m}=$ mass of the weight for desired stress level $(\mathrm{kg})$, $\mathrm{t}=$ thickness of bearing $(\mathrm{mm}), \mathrm{d}=$ diameter of the reduced section of the sample $(\mathrm{mm})$, and $\mathrm{L}=$ distance between the reduced section and the end of the bearing side $(\mathrm{mm})$.

On failure, the number of cycles displayed by the cycle counter was recorded. Thirty million cycles, which is approximately equivalent to 15 years of activity of a 
A
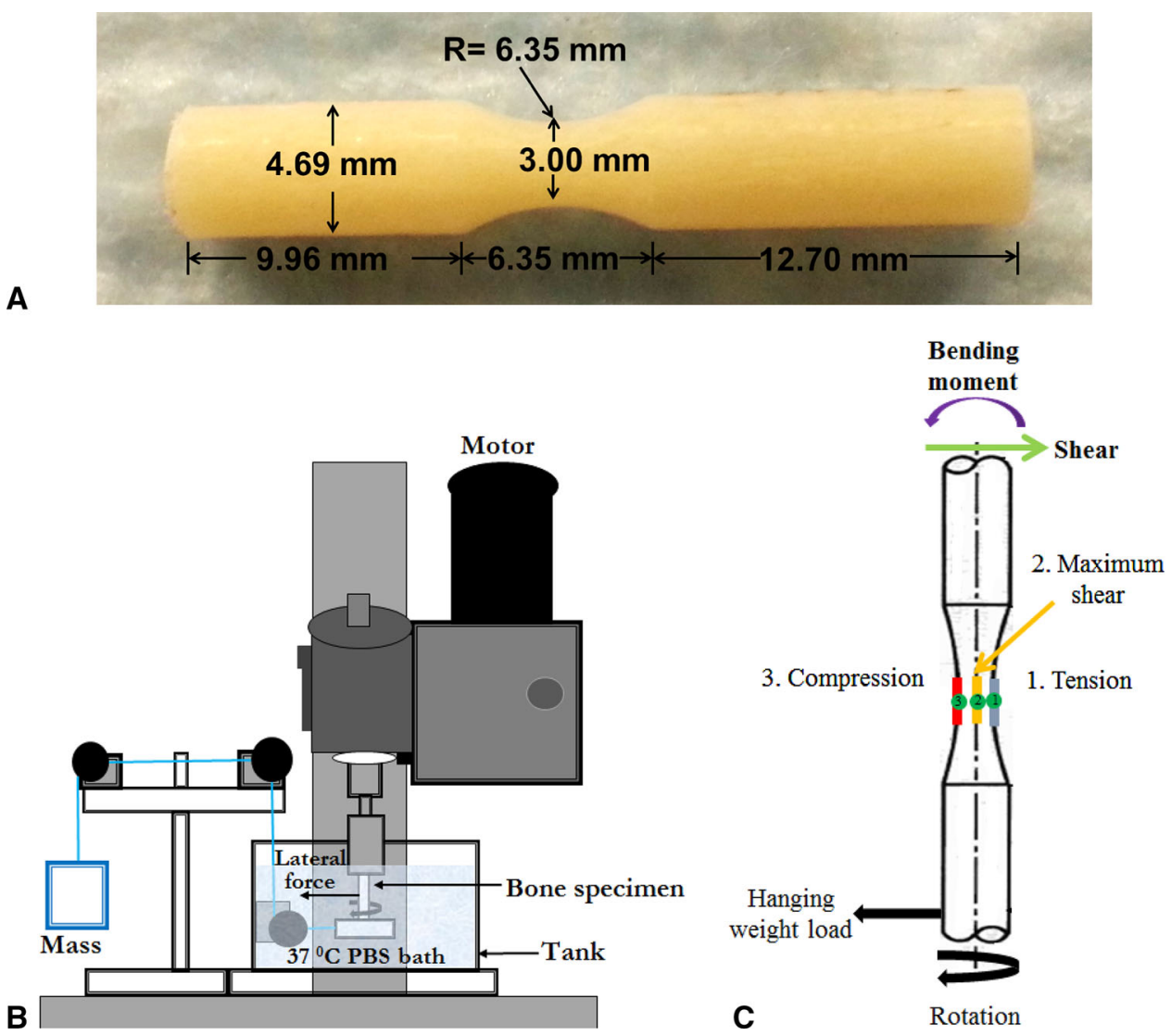

Fig. 1A-C (A) A rotating beam-bending specimen machined from the cortical bone and (B) a schematic representation of the custom rotating-bending fatigue testing apparatus used in our study are shown. PBS $=$ phosphate buffered saline. $(\mathbf{C})$ The loading profile of

moderately active person (assuming 6000 steps per day [68]) was defined as run-out. Run-out is nonfailure of a specimen after a certain number of cycles (in this case 30 million cycles). The mean cycles to failure for each group was calculated and plotted to create an S-N (stress vs cycles) plot for this study. All the specimens fractured in the gauge region.

Estimation of the High-cycle Fatigue Life of Radiationsterilized Cortical Bone

The loading experienced by specimens during rotatingbending fatigue-alternating tension and compression, with concentrated shear at the specimen core-is not unlike the multimodal nature of in vivo stresses experienced by allografts. As such, we assumed the loading during one step is approximately equivalent to one loading cycle in this study. The cycles to failure then can be converted to an estimated high-cycle fatigue life of the allograft knowing that the average person takes 6000 steps per day [68]. For example, if the rotating bending specimen is shown. During a $360^{\circ}$ rotation, any given point at the perimeter of the specimen experiences tension (blue), compression (red), and shear (green).

a sample failed after 6 million cycles the estimated allograft lifetime would be calculated as follows (Equation. 2).

1 cycle of loading $=1$ step

6 million cycles $\times\left(\frac{1 \text { day }}{6,000 \text { cycles }}\right)$

$$
\times\left(\frac{1 \text { year }}{365 \text { days }}\right) \approx 3 \text { years }
$$

The following equation can be manipulated and fit to points on the S-N curve to predict high-cycle fatigue behavior in the range of stress levels used in this study. In its exponential form:

$\sigma=A(N)^{b}$

$\sigma$ is the cyclic test stress level, $\mathrm{N}$ is the number of cycles to failure, $\mathrm{A}$ is the coefficient, and $\mathrm{b}$ is the exponent. Accordingly, a least-square fit of the log-log transform of the S-N results was done to obtain a mathematical function to estimate cycles to failure as a function of stress. 
Table 1. Mean cycles to failure and fold reduction between the control and irradiated groups

\begin{tabular}{|c|c|c|c|c|c|}
\hline \multirow[t]{2}{*}{ Stress level } & \multicolumn{2}{|l|}{ Control } & \multicolumn{2}{|l|}{ Irradiated } & \multirow{2}{*}{$\begin{array}{l}\text { Fold reduction between control } \\
\text { and irradiated groups }\end{array}$} \\
\hline & Data & Mean \pm SD & Data & Mean \pm SD & \\
\hline $25 \mathrm{MPa}$ & $\begin{array}{l}2.58 \times 10^{7} \\
3.07 \times 10^{7} \\
3.27 \times 10^{7} \\
3.12 \times 10^{7} \\
3.11 \times 10^{7} \\
3.05 \times 10^{7}\end{array}$ & $* *$ & $\begin{array}{l}1.14 \times 10^{7} \\
1.29 \times 10^{7} \\
6.51 \times 10^{5} \\
3.25 \times 10^{4} \\
5.94 \times 10^{6} \\
2.91 \times 10^{7}\end{array}$ & $(10.00 \pm 10.8) \times 10^{6}$ & $57.7 *$ \\
\hline $35 \mathrm{MPa}$ & $\begin{array}{l}1.18 \times 10^{7} \\
7.30 \times 10^{5} \\
2.60 \times 10^{6} \\
6.33 \times 10^{6} \\
1.75 \times 10^{7} \\
3.41 \times 10^{7}\end{array}$ & $(12.2 \pm 12.3) \times 10^{6}$ & $\begin{array}{l}5.39 \times 10^{5} \\
3.25 \times 10^{4} \\
1.90 \times 10^{6} \\
3.76 \times 10^{5} \\
1.47 \times 10^{5} \\
8.33 \times 10^{5}\end{array}$ & $(6.38 \pm 6.81) \times 10^{5}$ & 19.1 \\
\hline $45 \mathrm{MPa}$ & $\begin{array}{l}2.01 \times 10^{6} \\
3.56 \times 10^{5} \\
4.66 \times 10^{5} \\
5.44 \times 10^{5} \\
6.53 \times 10^{5} \\
3.52 \times 10^{5}\end{array}$ & $(7.31 \pm 6.39) \times 10^{5}$ & $\begin{array}{l}2.14 \times 10^{4} \\
5.76 \times 10^{4} \\
1.48 \times 10^{4} \\
5.48 \times 10^{4} \\
4.37 \times 10^{4} \\
5.79 \times 10^{4}\end{array}$ & $(4.17 \pm 1.91) \times 10^{4}$ & 17.5 \\
\hline $55 \mathrm{MPa}$ & $\begin{array}{l}5.02 \times 10^{4} \\
5.05 \times 10^{4} \\
1.02 \times 10^{5} \\
1.04 \times 10^{5} \\
5.14 \times 10^{4}\end{array}$ & $(7.16 \pm 2.86) \times 10^{4}$ & & & \\
\hline
\end{tabular}

** Five of six samples were run-outs in the control group, therefore, the mean and SD are not provided. As the 25 MPa control did not provide any mean, a higher stress level (55 MPa) test was performed for the control group only; *fold reduction at $25 \mathrm{MPa}$ was calculated by estimating the mean cycles to failure of $25 \mathrm{MPa}$ control by using the curve fit equation.

\section{Statistical Analysis}

The log-transformed fatigue data were found to be normal using the standard curve method [73]. A one-way ANOVA between treatment groups was performed (excluding the 25 MPa data as at $25 \mathrm{MPa}$ the control data had run-out samples) using Minitab ${ }^{\circledR}$ software (State College, PA, USA). The cycles to failure for the two treatment groups were compared at each level to determine statistically significant differences among their means using a 95\% CI. A post hoc analysis using the Tukey's test was conducted to compare pairwise differences among groups at each stress level. At $25 \mathrm{MPa}$ stress level, Kaplan-Meier survival analysis also was performed $[37,73]$. A post hoc power analysis was performed to confirm $90 \%$ power for different stress levels for $\mathrm{n}=6$ samples.

\section{Results}

There was a substantial reduction in fatigue life between the control and irradiated bone, with a difference of at least one order of magnitude at each stress level. In addition, the fatigue life decreases logarithmically as the cyclic stress amplitude increases for each treatment group. At $25 \mathrm{MPa}$, five of six of the control samples experienced run-out (Table 1), whereas all irradiated samples fractured at many fewer cycles to failure $\left(10.00 \times 10^{6} \pm 10.8 \times 10^{6}\right)$. According to Kaplan-Meier survival analysis, at $25 \mathrm{MPa}$, $83 \%$ control samples survived 30 million cycles (run-out) whereas $83 \%$ irradiated samples survived only 0.5 million cycles. At $35 \mathrm{MPa}$, irradiated samples showed an approximately 19-fold reduction in fatigue life compared with control samples $\left(12.2 \times 10^{6} \pm 12.3 \times 10^{6}\right.$ vs $6.38 \times 10^{5} \pm$ $\left.6.81 \times 10^{5} ; \mathrm{p}=0.046\right)$, and in the case of $45 \mathrm{MPa}$, this reduction was approximately 17.5 -fold $\left(7.31 \times 10^{5} \pm 6.39\right.$ $\times 10^{5}$ vs $4.17 \times 10^{4} \pm 1.91 \times 10^{4} ; \mathrm{p}=0.025$ ) (Fig. 2)

The estimated high-cycle fatigue life of control and radiation sterilized cortical bone for a certain stress can be expressed as:

$N_{\text {control }}=\left(\frac{\sigma}{145.04}\right)^{\frac{1}{-0.087}}$ 

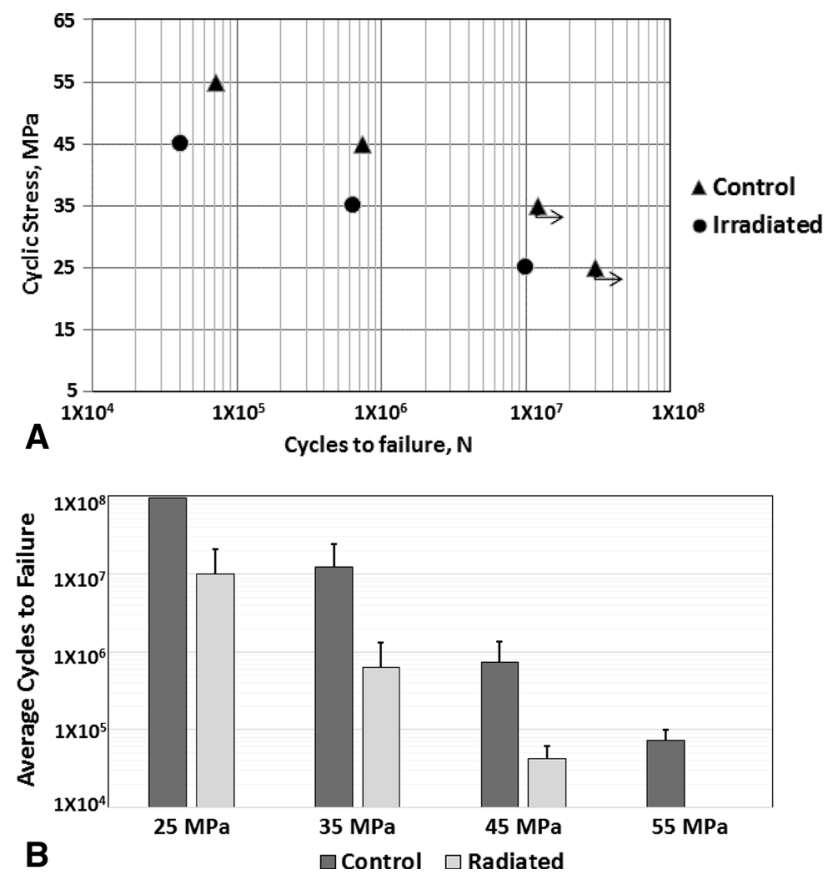

Fig. 2A-B (A) The mean cycles to failure for all treatment groups at stress levels of 45,35 , and $25 \mathrm{MPa}$ are shown. The SD bars are not shown for clarity. The arrows emanating from the control group at 25 MPa indicate multiple run-outs, and $35 \mathrm{MPa}$ indicates one run-out sample. For this study, run-out was set at 30 million cycles. At 25 MPa most of the control samples were run-outs. Therefore, to get the mean failure cycle at another stress level, a $55 \mathrm{MPa}$ group was added to the control group. (B) The mean cycles to failure for the treatment groups at different stress levels are shown. The error bars show the $\mathrm{SD}$. For the control group at $25 \mathrm{MPa}$, five of six samples were runouts, therefore, the mean and SD are not provided and the bar plot reaches the maximum limit. ( $\mathrm{n}=6$ samples [except for $55 \mathrm{MPa}, \mathrm{n}=5$ samples])

$N_{\text {irradiated }}=\left(\frac{\sigma}{130.08}\right)^{\frac{1}{-0.102}}$

As an example, if a sample is loaded at $35 \mathrm{MPa}$ then the predicted cycles to failure for the control are 12.5 million whereas for the irradiated samples only 0.4 million, showing that the equations are capable of predicting the in vitro life of cortical bone graft.

\section{Discussion}

Although it is known that the gamma radiation sterilization process impairs the mechanical properties of bone allografts $[2,4,6,12,22,35,55,66]$, there has not been a formal investigation, to our knowledge, of the high-cycle fatigue behavior of gamma-irradiated bone at physiologically relevant stress levels. Such information could be useful to gain insight into the extent to which the fatigue life of structural bone allograft may be compromised by gamma radiation sterilization. Our study showed that: (1) gamma radiation sterilization induces a dramatic reduction in the high-cycle fatigue life of cortical bone; and, (2) at higher stress levels the high-cycle fatigue life of irradiated cortical bone decreases more dramatically than with lower stress levels.

This study has some obvious limitations. The specimens were machined from six femurs from six male donors (age range, 36-65 years). Although clearly the bone samples would be expected to have different properties based on age differences alone, the samples were uniformly distributed over the two groups by donor and by the bone quadrants (anterior, posterior, medial, lateral) from which the specimens were machined. This scheme of assignment was used to reduce potential bias introduced by donor-todonor variations between the two experimental groups. Additionally this in vitro model does not account for the biologic integration of grafts during which the graft is resorbed and replaced by new bone formation. However, it is known that integration of larger bone allografts is limited to the periphery after a long period [13, 18, 27-29, 33]. Therefore, it is possible that the majority of the volume of the original graft resides in the body for years without being remodeled and yet it will experience loading during its service in vivo. We expect any remodeling to increase the longevity of allografts. Therefore, the results of this study can be considered to represent the worst case scenario in which little or no remodeling taking place. Finally, in this study all samples were tested at $30 \mathrm{~Hz}$. Strain rate influences the fatigue life of cortical bone and it has been shown that at higher test frequencies fatigue life increases $[48,49]$. A substantial amount of bone fatigue data are obtained at frequencies which are greater than the expected in vivo stress frequencies (ie, 2-3 Hz) [20, 38, 53]. At less than $30 \mathrm{~Hz}$, it has been observed that the effect of frequency on the fatigue life is negligible [48, 49]. Therefore, data obtained at frequencies greater than $30 \mathrm{~Hz}$ would be expected to overestimate the functional fatigue life cycle of the samples. At $30 \mathrm{~Hz}$, strain rates of 0.0375 and 0.0675 per second are in effect at stress amplitudes of 25 and 45 $\mathrm{MPa}$, respectively. This range is in agreement with those reported for the lower limbs physiologically for walking $(0.01 /$ second) to more strenuous stair climbing activity (0.08/second) [1, 20, 36].

To our knowledge, this is the first report of high-cycle fatigue behavior for control and gamma-irradiated bone tissue. There was a loss in fatigue life with radiation sterilization because of the damage that occurs to the collagen matrix with irradiation owing to the scission of the peptide backbone of the collagen molecule and others have reported losses in mechanical properties with gamma radiation sterilization $[2,4,6,12,22,35,55,66]$. Therefore, it was not surprising to find a loss of high-cycle 
Table 2. Comparison of study results

\begin{tabular}{lllllc}
\hline Study & Exponent, b & Coefficient, A & Specimen & Fatigue test loading mode & Frequency (Hz) \\
\hline Lafferty and Raju [49] & -0.13 & 318 & Bovine cortical & Rotating bending & 30 \\
Current study & -0.087 & 145.04 & Human cortical & Rotating bending & 30 \\
Current study & -0.102 & 130.08 & Irradiated human cortical & Rotating bending & 30 \\
Lafferty and Raju [49] & -0.124 & 331 & Bovine cortical & Rotating bending & 60 \\
Swanson et al. [64] & -0.095 & 210.74 & Human cortical & Rotating bending & 70 \\
Carter and Hayes [16] & -0.136 & 405.6 & Bovine cortical & Rotating bending & 125 \\
\hline
\end{tabular}

fatigue life between control and gamma-irradiated bone tissue. In vivo stress in human femur ranges from $10 \mathrm{MPa}$ to $23 \mathrm{MPa}$ during normal walking depending on the location [7, 40]. This in vivo stress can increase to $26 \mathrm{MPa}$ to $40 \mathrm{MPa}$ during stair climbing or other rigorous movements [7, 23]. Therefore, it is likely that bone allografts used in our study experienced stress amplitudes. Stress elevation is particularly possible when the allograft is undersized or it contains a stress riser such as a hole. Defects in the forms of microcracks, which are naturally present, also may amplify local stresses. Overall, the stress amplitudes used in this study are in general accordance with in vivo stress amplitudes.

To predict the high-cycle fatigue life of a bone allograft, it is necessary to establish the S-N (stress versus number of cycles) curve which is the fundamental step in characterizing the fatigue performance of any material. In this study, samples were loaded in cyclic fatigue at three stress levels. The S-N plot (Fig. 2A) for control and irradiated samples were fit with linear least-square regression to generate an empirical analytic model which can estimate the high-cycle fatigue life of an irradiated cortical bone allograft. These curves allow prediction of the lifetime of a component at a particular stress level. To our knowledge, this is the first time that sufficient high-cycle fatigue data have been collected to be able to model the fatigue life of irradiated human cortical bone at a physiologically relevant frequency level, loading conditions, and testing conditions (in PBS at $37{ }^{\circ} \mathrm{C}$ ). The comparison table indicates that the results from these data fill the gap in the existing literature (Table 2) [16, 49, 64]. The duty cycles experienced by bones of the lower limb (thus, presumably, an implanted allograft) can be estimated by the number of steps taken per day which ranges from less than 5000 (sedentary) to 12,500 (highly active) [67, 68]. At such rates, the total number of loading cycles per year amount to from 2 million to 5 million. It may take several years for small bone grafts to be resorbed and replaced whereas massive allografts can be considered to be permanent. Therefore, for practical purposes, a reasonable functional fatigue limit for grafts should be at least 25 million cycles, which corresponds to 12.5 years in a sedentary person and 5 years in a highly active person. Currently, we do not know whether a bone sterilized at $25 \mathrm{kGy}$ will meet these requirements at stress levels observed in vivo. This study establishes an S-N plot and equation to predict the high-cycle fatigue life of a bone allograft sterilized with $25 \mathrm{kGy}$ gamma radiation at in vivo stress levels. For example, using the information from our study and assuming $25 \mathrm{MPa}$ loads are experienced by a sedentary person, we may predict that, if there is no integration or remodeling taking place, a cortical bone allograft sterilized at $25 \mathrm{kGy}$ will not last 12.5 years; the functional lifetime of that bone allograft will be 11 million cycles which is equivalent to 5.5 years.

The specimens from donor femurs experienced $1250 \mu \varepsilon$ to $2250 \mu \varepsilon$ strain amplitudes during the $25 \mathrm{MPa}$ and 45 MPa stress level tests in this study. The in vivo strain in the femur during walking and to stair climbing to running varies from $1200 \mu \varepsilon$ to $2000 \mu \varepsilon$ [20]. Therefore, the strain range of this study varies over the physiologic strain range and (ignoring the complexity of biologic activity and loading conditions), the result of this study can be an approximate estimation to predict high-cycle fatigue life of structural allograft. The findings of our study show that gamma radiation sterilization diminishes the high-cycle fatigue behavior of human cortical bone tissue under physiologically relevant in vitro loading and environmental conditions. Monotonic tests of irradiated allografts show that strength, Young's modulus, and ductility decline in the range of two- to threefold [22, 32, 35]. In contrast, fatigue life of irradiated structural allografts may decline by more than 15-fold and this dramatic decline should be taken into consideration. Methods to reduce the effect of irradiation or recover allograft strength therefore remain important to pursue. Irradiated bone allograft can be subjected to free radical scavenger treatment or crosslinking agents to restore some of the strength of the collagen backbone after testing $[3,39,58,61,62]$. Our study provides an S-N relationship at standard radiation dose, which can be useful in future studies that seek to maintain allograft strength after sterilization.

Acknowledgments We thank the Musculoskeletal Transplant Foundation (Edison, NJ, USA) for providing the femurs. 


\section{References}

1. Aamodt A, Lund-Larsen J, Eine J, Andersen E, Benum P, Husby OS. In vivo measurements show tensile axial strain in the proximal lateral aspect of the human femur. $J$ Orthop Res. 1997;15:927-931.

2. Akkus O, Belaney RM. Sterilization by gamma radiation impairs the tensile fatigue life of cortical bone by two orders of magnitude. J Orthop Res. 2005;23:1054-1058.

3. Akkus O, Belaney RM, Das P. Free radical scavenging alleviates the biomechanical impairment of gamma radiation sterilized bone tissue. J Orthop Res. 2005;23:838-845.

4. Akkus O, Rimnac CM. Fracture resistance of gamma radiation sterilized cortical bone allografts. J Orthop Res. 2001;19:927-934.

5. Alaneme K. Design of a cantilever-type rotating bending fatigue testing machine. J Miner Mater Characterization Eng. 2011;10:1027-1039.

6. Anderson MJ, Keyak JH, Skinner HB. Compressive mechanical properties of human cancellous bone after gamma irradiation. J Bone Joint Surg Am. 1992;74:747-752.

7. Andreaus U, Colloca M, Toscano A. Mechanical behavior of a prosthetized human femur: a comparative analysis between walking and stair climbing by using the finite element model. Biophys Bioeng Letters. 2008;1:1-15.

8. Aspenberg P, Johnsson E, Thorngren KG. Dose-dependent reduction of bone inductive properties by ethylene oxide. $J$ Bone Joint Surg Br. 1990;72:1036-1037.

9. ASTM International. Standard Practice for Conducting Force Controlled Constant Amplitude Axial Fatigue Tests of Metallic Materials. Available at: http://www.astm.org/Standards/E466. htm. Accessed July 1, 2015.

10. Bailey AJ. Irradiation-induced changes in the denaturation temperature and intermolecular cross-linking of tropocollagen. Radiat Res. 1967;31:206-214.

11. Bakhach J. The cryopreservation of composite tissues: principles and recent advancement on cryopreservation of different type of tissues. Organogenesis. 2009;5:119-126.

12. Bright RW, Burchardt $\mathrm{H}$. The biomechanical properties of preserved bone grafts. In Friedlander GE, Mankin HJ, Sell KW, eds. Osteochondral Allografts: Biology, Banking and Clinical Applications. Boston, MA: Little, Brown and Company; 1984:241247.

13. Burchardt H, Jones H, Glowczewskie F, Rudner C, Enneking WF. Freeze-dried allogeneic segmental cortical-bone grafts in dogs. J Bone Joint Surg Am. 1978;60:1082-1090.

14. Campbell DG, Li P, Stephenson AJ, Oakeshott RD. Sterilization of HIV by gamma irradiation: a bone allograft model. Int Orthop. 1994;18:172-176.

15. Carpenter EM, Gendler E, Malinin TI, Temple HT. Effect of hydrogen peroxide on osteoinduction by demineralized bone. AmJ Orthop (Belle Mead NJ). 2006;35:562-567.

16. Carter DR, Hayes WC. Fatigue life of compact bone: I. Effects of stress amplitude, temperature and density. J Biomech. 1976;9:2730.

17. Carter DR, Hayes WC. Compact bone fatigue damage: I. Residual strength and stiffness. J Biomech. 1977;10:325-337.

18. Chalmers J. Transplantation immunity in bone homografting. J Bone Joint Surg Br. 1959;41:160-179.

19. Cheung DT, Perelman N, Tong D, Nimni ME. The effect of gamma-irradiation on collagen molecules, isolated alpha-chains, and crosslinked native fibers. J Biomed Mater Res. 1990;24:581589.

20. Cowin SC, Moss ML. Mechanosensory mechanisms in bone. In Cowin SC, ed. Bone Mechanics Handbook. 2nd ed. Boca Raton, FL: 2001; 209, 255-272,766.
21. Crawford RJ, Benham PP. A comparison of uniaxial and rotating bending fatigue tests on an acetal co-polymer. J Mater Sci. 1974;9:1297-1304.

22. Currey JD, Foreman J, Laketic I, Mitchell J, Pegg DE, Reilly GC. Effects of ionizing radiation on the mechanical properties of human bone. J Orthop Res. 1997;15:111-117.

23. D'Lima DD, Steklov N, Fregly BJ, Banks SA, Colwell CW Jr. In vivo contact stresses during activities of daily living after knee arthroplasty. J Orthop Res. 2008;26:1549-1555.

24. DePaula CA, Truncale KG, Gertzman AA, Sunwoo MH, Dunn MG. Effects of hydrogen peroxide cleaning procedures on bone graft osteoinductivity and mechanical properties. Cell Tissue Bank. 2005;6:287-298.

25. Doherty MJ, Mollan RA, Wilson DJ. Effect of ethylene oxide sterilization on human demineralized bone. Biomaterials. 1993;14:994-998.

26. Domínguez Almaraz GM, Ávila Ambriz JL, Cadenas Calderón E. Fatigue endurance and crack propagation under rotating bending fatigue tests on aluminum alloy AISI 6063-T5 with controlled corrosion attack. Engineering Fracture Mechanics. 2012;93:119131.

27. Enneking WF, Campanacci DA. Retrieved human allografts: a clinicopathological study. J Bone Joint Surg Am. 2001;83:971986.

28. Enneking WF, Mindell ER. Observations on massive retrieved human allografts. J Bone Joint Surg Am.1991;73:1123-1142.

29. Enneking WF, Morris JL. Human autologous cortical bone transplants. Clin Orthop Relat Res. 1972;87:28-35.

30. Fölsch C, Mittelmeier W, Bilderbeek U, Timmesfeld N, von Garrel T, Peter Matter H. Effect of storage temperature on allograft bone. Transfus Med Hemother. 2012;39:36-40.

31. Gallie WE. The use of boiled bone in operative surgery. Am J Orthop Surg. 1918;16:373-383.

32. Godette GA, Kopta JA, Egle DM. Biomechanical effects of gamma irradiation on fresh frozen allografts in vivo. Orthopedics. 1996;19:649-653.

33. Goldberg VM, Stevenson S. The biology of bone grafts. Semin Arthroplasty. 1993;4:58-63.

34. Hamer AJ, Stockley I, Elson RA. Changes in allograft bone irradiated at different temperatures. J Bone Joint Surg Br. 1999;81:342-344.

35. Hamer AJ, Strachan JR, Black MM, Ibbotson CJ, Stockley I, Elson RA. Biochemical properties of cortical allograft bone using a new method of bone strength measurement: a comparison of fresh, fresh-frozen and irradiated bone. J Bone Joint Surg Br. 1996;78:363-368.

36. Hansen U, Zioupos P, Simpson R, Currey JD, Hynd D. The effect of strain rate on the mechanical properties of human cortical bone. J Biomech Eng. 2008;130:011011.

37. Kaplan EL, Meier P. Nonparametric estimation from incomplete observations. J Am Stat Assoc. 1958;53:457-481.

38. Karl M, Kelly JR. Influence of loading frequency on implant failure under cyclic fatigue conditions. Dent Mater. 2009;25: 1426-1432.

39. Kattaya SA, Akkus O, Slama J. Radioprotectant and radiosensitizer effects on sterility of gamma-irradiated bone. Clin Orthop Relat Res. 2008;466:1796-1803.

40. Keyak JH, Meagher JM, Skinner HB, Mote CD Jr. Automated three-dimensional finite element modelling of bone: a new method. J Biomed Eng. 1990;12:389-397.

41. Knaepler H, Haas H, Püschel HU. [Biomechanical properties of heat and irradiation treated spongiosa][in German]. Unfallchirurgie. 1991;17:194-199.

42. Knaepler H, von Garrel T, Seipp HM, Ascherl R. [Experimental studies of thermal disinfection and sterilization of allogeneic 
bone transplants and their effects on biological viability][in German]. Unfallchirurg. 1992;95:477-484.

43. Knez M, Glodež S, Ružička M, Kramberger J. A rotating bending approach for determination of low-cycle fatigue parameters. Int $J$ Fatigue. 2010;32:1724-1730.

44. Kohler P, Glas JE, Larsson S, Kreicbergs A. Incorporation of nonviable bone grafts: autoclaved autogeneic and frozen allogeneic bone grafts compared in the rabbit. Acta Orthop Scand. 1987;58:54-60.

45. Kohler P, Kreicbergs A, Stromberg L. Physical properties of autoclaved bone: torsion test of rabbit diaphyseal bone. Acta Orthop Scand. 1986;57:141-145.

46. Komender A. Influence of preservation on some mechanical properties of human haversian bone. Mater Med Pol. 1976;8:1317.

47. Kudryk VL, Scheidt MJ, McQuade MJ, Sutherland DE, VanDyke TE, Hollinger JO. Toxic effect of ethylene-oxide-sterilized freeze-dried bone allograft on human gingival fibroblasts. J Biomed Mater Res. 1992;26:1477-1488.

48. Lafferty JF. Analytical model of the fatigue characteristics of bone. Aviat Space Environ Med. 1978;49:170-174.

49. Lafferty JF, Raju PV. The influence of stress frequency on the fatigue strength of cortical bone. J Biomech Eng. 1979;101:112113.

50. Lietman SA, Tomford WW, Gebhardt MC, Springfield DS, Mankin HJ. Complications of irradiated allografts in orthopaedic tumor surgery. Clin Orthop Relat Res. 2000;375:214-217.

51. Mitchell EJ, Stawarz AM, Kayacan R, Rimnac CM. The effect of gamma radiation sterilization on the fatigue crack propagation resistance of human cortical bone. J Bone Joint Surg Am. 2004;86:2648-2657.

52. Moore E. The Frequency, Aqueous Solution, Stress Amplitude, Temperature (FAST) Machine: A Device Proposed for Accelerated Fatigue Testing of Cortical Bone. Columbus, OH: Case Western Reserve University; 2012. Available at: https://etd.ohiolink. edu/ap/10?0::NO:10:P10_ACCESSION_NUM:case1339170465. Accessed September 29, 2015.

53. Moore TL, Gibson LJ. Fatigue of bovine trabecular bone. $J$ Biomech Eng. 2003;125:761-768.

54. Munting E, Wilmart JF, Wijne A, Hennebert P, Delloye C. Effect of sterilization on osteoinduction: comparison of five methods in demineralized rat bone. Acta Orthop Scand. 1988;59:34-38.

55. Nguyen H, Morgan DF, Forwood M. Sterilization of allograft bone: effects of gamma irradiation on allograft biology and biomechanics. Cell Tissue Bank. 2007;8:93-105.

56. Pekkarinen T, Hietalal O, Jamsa T, Jalovaara P. Gamma irradiation and ethylene oxide in the sterilization of native reindeer bone morphogenetic protein extract. Scand J Surg. 2005;94:6770.

57. Prolo DJ. Oklund SK, Borer M. Efficacy and safety of ethylene oxide sterilization of allogeneic bone for human transplantation: a forty-year experience. Cureus. 2013;5:e121.
58. Reich MS, Akkus O. Sporicidal efficacy of genipin: a potential theoretical alternative for biomaterial and tissue graft sterilization. Cell Tissue Bank. 2013;14:381-393.

59. Russell N, Rives A, Bertollo N, Pelletier MH, Walsh WR. The effect of sterilization on the dynamic mechanical properties of paired rabbit cortical bone. J Biomech. 2013;46:1670-1675.

60. Salehpour A, Butler DL, Proch FS, Schwartz HE, Feder SM, Doxey CM, Ratcliffe A. Dose-dependent response of gamma irradiation on mechanical properties and related biochemical composition of goat bone-patellar tendon-bone allografts. $J$ Orthop Res. 1995;13:898-906.

61. Seto A, Gatt CJ Jr, Dunn MG. Radioprotection of tendon tissue via crosslinking and free radical scavenging. Clin Orthop Relat Res. 2008;466:1788-1795.

62. Seto A, Gatt CJ Jr, Dunn MG. Improved tendon radioprotection by combined cross-linking and free radical scavenging. Clin Orthop Relat Res. 2009;467:2994-3001.

63. Stroosma OC, Klopper PJ, van den Hooff A. Boiled and unboiled detached autogenous bone fragments: an experimental study. Neth J Surg. 1986;38:112-117.

64. Swanson SA, Freeman MA, Day WH. The fatigue properties of human cortical bone. Med Biol. Eng. 1971;9:23-32.

65. Thoren K, Aspenberg P. Ethylene oxide sterilization impairs allograft incorporation in a conduction chamber. Clin Orthop Relat Res. 1995;318:259-264.

66. Triantafyllou N, Sotiropoulos E, Triantafyllou JN. The mechanical properties of the lyophilized and irradiated bone grafts. Acta Orthop Belg. 1975;41(suppl 1):35-44.

67. Tudor-Locke C, Hatano Y, Pangrazi RP, Kang M. Revisiting "how many steps are enough?". Med Sci Sports Exerc. 2008;40(7 suppl):S537-543.

68. Tudor-Locke CE, Myers AM. Methodological considerations for researchers and practitioners using pedometers to measure physical (ambulatory) activity. Res Q Exerc Sport. 2001;72:1-12.

69. Tufekci K, Kayacan R, Kurbanoglu C. Effects of gamma radiation sterilization and strain rate on compressive behavior of equine cortical bone. J Mech Behav Biomed Mater. 2014;34:231-242.

70. Wilkins RM, Gitelis S, Hart RA, Gross AE. Human allograft bone processing and safety. AAOS Now. Available at: http:// www.aaos.org/news/aaosnow/mar13/research2.asp. Accessed September 29, 2015.

71. Yamamoto T, Uchida K, Naruse K, Suto M, Urabe K, Uchiyama K, Suto K, Moriya M, Itoman M, Takaso M. Quality assessment for processed and sterilized bone using Raman spectroscopy. Cell Tissue Bank. 2012;13:409-414.

72. Yasin NF, Ajit Singh V, Saad M, Omar E. Which is the best method of sterilization for recycled bone autograft in limb salvage surgery: a radiological, biomechanical and histopathological study in rabbit. BMC Cancer. 2015;15:289.

73. Yeni YN, Poisson LM, Flynn MJ. Heterogeneity of bone mineral density and fatigue failure of human vertebrae. J Biomech. 2013;46:1396-1399. 